\title{
Similarities between odor mixtures with known components
}

\author{
ROBERT A. M. GREGSON \\ University of New England, Armidale, Australia
}

\begin{abstract}
Similarities between two-component odor mixtures, of known and controlled composition, were modeled by two alternative theories, one based on distances and the other on set theoretical measures. Odor substances used were n-butanol, amyl acetate, heptanol, and citronellal, in a continuous-flow dilution olfactometer with two independently controlled channels. It was found, in confirmation of previous results, that the similarity judgments are best predicted from the set theoretical model. Special complications arising in olfaction due to possible component masking and interaction are noted.
\end{abstract}

Studies of similarities between complex stimuli have employed a diversity of scaling models and associated algorithms to represent what the human observer does in such tasks (Gregson, 1975, 1976; Lopes \& Oden, 1980; Shepard \& Arabie, 1979; Tversky, 1977), but relatively few workers have used controlled odor mixtures as stimuli.

Similarities between complex odors, each of which may be chemically a mixture and not a compound, and each of which could elicit complex sensory experiences, are reported both in the industrial research of perfume makers and in basic psychometric research (Amoore \& Venstrom, 1967; Davis, 1977, 1979; Gregson, 1972; Jones, Roberts, \& Holman, 1978; Schiffman, Robinson, \& Erickson, 1977; Woskow, 1964; Wright \& Michels, 1964; Yoshida, 1972), but such experiments are usually performed because there exists no prior specification of the complex stimuli as perceived, and it is required to find a representation of each odor as a vector in a minimum dimensionality space. This is the objective of multidimensional scaling (m.d.s.).

In contradistinction, experiments to predict what the scaled similarity of odor pairs would be, given that the composition of each odor in a pair is quantitatively known and controllable, have as objective the testing of parametrized multivariate psychological models. Knowing the stimulus specification turns the problem into an extension of psychophysics, with special provision for mechanisms of component interaction (Gregson, 1980a), which obviously do not operate in unidimensional situations.

This work was supported financially by the Australian Research Grants Scheme in 1981 and 1982. Mark Burton and Jane Slater assisted with data collection and processing. An earlier version of this paper was presented at the 16th Mathematical Psychology Conference, University of Colorado, August 1983. The author's mailing address is: Department of Psychology, University of New England, Armidale, 2351 Australia.
Special interest centers on the consequent possibility of testing models of similarity that are derived from assumptions about their metric or set theoretic form, or from m.d.s. results, by turning the problem around and seeing if a given model (with flexible parameter estimation) will predict from a known physiochemical stimulus specification to a known psychological similarity response instead of, as in the m.d.s. case, from a known response working to a construction of an inferred, but unobservable, stimulus representation, again assuming a model structure.

There is an additional complication, not necessarily specific to olfaction: the components of a created odor mixture can themselves be complex substances, such as natural essences. The only variable that is manipulable is the proportion of a component in a mixture. Hence, the components are themselves stimuli which could have been used as input to an m.d.s. experiment. In such an experiment, the similarity between the components would be judged.

In the results to be reported here, the stimuli were all two-component mixtures chosen so that the components were qualitatively discriminable when presented as single odors. Only similarities between mixtures were elicited.

The model chosen as the starting point is given in Equation 1. In a comparison of two mixtures, $\mathbf{i}, \mathbf{j}$, which have component odors in concentrations $\left(m_{i l}\right.$, $\left.m_{i 2}\right)$ and $\left(m_{j 1}, m_{j 2}\right)$, respectively, and in which $w_{1}, w_{2}$ are real positive scalar weights (the adjustable parameters of the model), the theoretical similarity, ${ }^{1}$

$$
\begin{aligned}
& \mathscr{P}(\mathrm{i}, \mathrm{j}) \\
& =\frac{\mathrm{w}_{1}\left[\min \left(\mathrm{m}_{\mathrm{i} 1}, \mathrm{~m}_{\mathrm{j} 1}\right)\right]^{\mathrm{w}_{2}}+\mathrm{w}_{1}^{-1}\left[\min \left(\mathrm{m}_{\mathrm{i} 2}, \mathrm{~m}_{\mathrm{j} 2}\right)\right]^{\mathrm{w}_{2}}}{\mathrm{w}_{1}\left[\max \left(\mathrm{m}_{\mathrm{i} 1}, \mathrm{~m}_{\mathrm{j} 1}\right)\right]^{\mathrm{w}_{2}}+\mathrm{w}_{1}{ }^{-1}\left[\max \left(\mathrm{m}_{\mathrm{i} 2}, \mathrm{~m}_{\mathrm{j} 2}\right)\right]^{\mathrm{w}_{1}}} .
\end{aligned}
$$

This model (1) has a reasonable prior probability of fitting similarity data with only two free param- 
eters $\left(w_{1}, w_{2}\right)$. It is a variant of Equation 5.44.1 in Gregson (1975). This form is not the same as a cityblock model but numerically is not very different; it does not have the same isosimilarity contours (Gregson, 1976).

Equation 1 is a ratio of set intersection measures divided by set union measures, where the $m$ are interpreted as measures on sets. The similarity thus defined ranges over the closed interval $(0,1)$, taking the value 1 when the two stimulus mixtures $i, j$ are identical. The weights are defined as real positive scalars and in practice would be expected to take values in a constrained range for consistent data. The $w$ are defined in physical stimulus terms, so that the w may combine two roles, as tranformations from physical to psychological magnitudes and as bias parameters. The value of $\mathscr{S}(i, j)$ can become zero only if the minima on each sensory dimension are both zero.

An alternative assumption, explicit in some multidimensional scalings in Euclidean space that have been used in olfaction, is to map the similarities between mixtures into distances between the mixtures where the latter are defined as vectors in a twodimensional component concentration space. Using, as a definition,

$$
d(i, j)=\left|\sum_{h=1}^{2} v_{h}\left(m_{i h}-m_{j h}\right)^{2}\right|^{1 / 2},
$$

where $v_{1}=w_{1}, v_{2}=w_{1}^{-1}$, then

$$
\mathscr{S}(\mathrm{i}, \mathrm{j})=1 /\left\{\exp [\mathrm{d}(\mathrm{i}, \mathrm{j})]^{\mathrm{w}_{2}}\right\},
$$

which, without free parameters $w$, is given as Equation 6.22.2 in Gregson (1975).

In the first experiment reported here, an unconstrained comparison of the two models $(1)$ and $(2,3)$ is reported. In the second, a specific property which distinguishes the two models is used to test their relative fit.

\section{GENERAL METHOD}

Two experiments are reported here, the procedure in all major details in the two is the same, except that the actual odorants used here changed in one component in the second study, and the set of concentrations was composed differently within the same range limits. Common details of procedure are given only once, and the rationale for the differences between the two experiments is given in the discussion of the first.

\section{Apparatus}

The stimuli were generated and presented in the air-conditioned, specially constructed odor psychophysics laboratory at the University of New England, using a continuous-flow bypass olfactometer with the facility to create two separate, controlled odor streams and then to combine them into one mixed flow for the observer to sample.
The air, supplied to the olfactometer by a blower, is filtered through glass fiber, silica gel, molecular sieve, and glass fiber. The main flow of clean air then passes at not more than 160 liters/ min through a Fisher $\mathbf{2 0 0 0}$ flowmeter; subsidiary flows $X$ and $Y$ are drawn off through a set of four Fisher 1100 meters in parallel, covering, as desired, the ranges $20-200 \mathrm{ccs} / \mathrm{min}$ and $100-$ $1,000 \mathrm{ccs} / \mathrm{min}$. The flow from these meters is passed through spargers under the liquid odorant surface and then into $250-\mathrm{ml}$ diffusion chambers packed with glass fiber to suppress aerosol effects if they occur, before entering a venturi to mix with the main flow. The running temperature is stable around $22^{\circ} \mathrm{C}$. The flowmeters control the odor concentration in the presented stimulus mixtures.

The major components were glass or polytetrafluorethylene in the flow lines, and perspex or aluminum foil in the chamber in which the subject sat to sample odorous air from a special chamber, also made of perspex. The observer was thus seated in a space, about $130 \times 170 \times 200 \mathrm{~cm}$, with controlled airflow regulated by a fan. The odorous air created by the olfactometer was constrained in a vertical $20 \times 30 \times 80 \mathrm{~cm}$ perspex chamber, which was swept out at least three times a minute by the flow rates used, and did not mix with the atmosphere of the subject's environment. It was sampled by the subject's putting his/her nose against a flap in the wall of this small chamber and briefly deflecting some odorous air up the nostrils.

\section{EXPERIMENT 1}

The data reported here are only part of a larger study, which also involved intensity ratings in the same stimulus series presented at different sessions. Those data are analyzed separately elsewhere, as a problem in multivariate time series (Gregson, 1982, 1983). Their existence is noted here because the earlier sessions could have had some effect in stabilizing performance in the similarity task.

\section{Method}

The similarity responses were collected in two of five sessions for each subject; the same flowmeter settings of a random series of mixtures were used for different sessions, but with various odorants. Thus, the same series served to provide component intensity ratings ( 2 responses per stimulus, 112 responses in all) and similarity judgments ( 1 response for each pair of successive stimuli, 28 responses in all).

To create the 56 mixtures, as a random walk in two dimensions, eight flow settings, in the range of $20-800 \mathrm{ml} / \mathrm{min}$, were selected for the $X$ line and another eight slightly different ones were selected for the $Y$ line, giving 64 possible mixtures. A subset of 8 mixtures with extreme values was deleted, and the remaining 56 were presented once each with no constraints on the sequence. The physical concentrations expressed in volume of saturated odor flow to volume of main filtered airflow ranged from about $1.25 \times 10^{4}$ to about $50 \times 10^{-4}$. The three odorants, butanol, heptanol, and amyl acetate were used in a balanced allocation to flowlines $X$ and $Y$, as given in Table 1 . In each mixture $X$ precedes $Y$. Only the results for the 12 similarity judgment sessions are presented here; the total design is given to show the extent of prior stimulus exposure subjects had in the task situation, either on intensity ratings or on similarity assessment.

The subjects were paid volunteers, aged between 18 and 26 years, with no special experience in olfaction experiments.

The instructions to the subjects are reproduced here in full, as their form can be critical in similarity experiments.

"In this experiment there are 56 trials which are spaced at halfminute intervals. On each trial you have to sniff, lightly, the odorstream for 3 seconds. The odorstream usually has two components in it, one or the other may not always be detectable on every trial. The intensities of the components vary from trial to trial. 


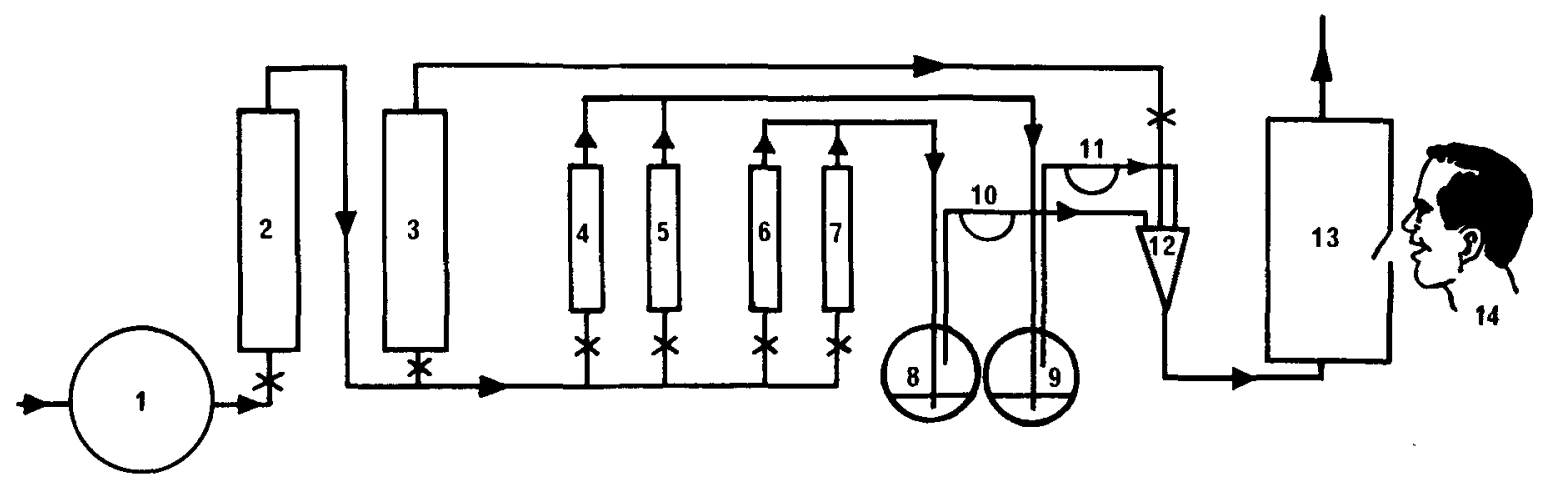

Figure 1. Schematic drawing of olfactometer. Key to numbered items: 1, main input air blower; 2 , main air filter; 3 , flowmeter, 160 liters/min clean-air supply; 4, 5, 6, 7, small flowmeters, range $0-1,000 \mathrm{ml} / \mathrm{min}$ for low and high settings;8,9, flasks containing odorous liquids (airflow passes through sparges); 10, 11, filters to trap aerosol particles; 12, Venturi to mix airflows; 13, odorous air sampling chamber; 14 , observer putting nose to flap in wall of $13 ; \mathrm{X}$, control valves.

\begin{abstract}
"You will be given each of the two component odors, in turn, in pure form, as a familiarization before the trials begin. You may personally give these two odors any names you like to help remember them, but in the similarity task you will not be asked to judge them separately, only to assess mixtures as wholes.

"In this session you will get the odor mixtures presented in pairs; first one mixture, then the other. The time interval between the two has to be about 25 seconds. You will need to carry in your memory your impression of the first mixture in order to compare it with the second one. After you have sniffed both of the two mixtures in a pair, then you rate the pair on a scale of similarity which runs from zero to 100 . 'Zero' means the two odor mixtures were completely different. ' 100 ' means they were exaactly the same. Use any number you think appropriate within the total range from 0 to 100 .

"Note that you only make a response on your record sheet after every even-numbered odor mixture, 28 responses in all to the series of 28 pairs, or 56 odors.

"Please note, not all odors smell the same to all observers; you will get the two odors in pure and most intense form, each in turn, at the start. You may personally give the odors any description you wish in order to help you to remember and to distinguish them throughout the series of 56 presentations of mixtures."
\end{abstract}

\section{Results}

Raw data are, on a single session, $28 \times 4$ stimulus component concentrations, scaled in milliliters/ minute flow, and 28 similarity judgments, on a scale from 0 to 100 . The analysis consists of minimizing residual differences between theoretical and observed similarities, $\mathscr{S}$, scaled to lie $0<\mathscr{P}<1$ given a priori a model of fixed structure and adjustable parameters, w. The parameter set that minimizes the root mean square residual error, $\mathrm{E}$, for a given subject must also yield a regression of observed on theoretical similarities that approaches a linear (identity) transformation. Solutions across a set of subjects-by adding axioms concerning the probability distribution of parameters across observers or across odorants-are possible but are not pursued here. Directly pooling data across subjects to estimate parameters is meaningless.

Previous studies (Gregson, 1976; Mitchell, 1971) had found Model 1 to be at least as valid as other alternatives when compared with a range of combinations of intra- and interdimensional pooling and con- trasts, given the available stimulus information, the task constraints, and the lack of general information on the psychometrics of olfaction. By introducing more terms and free parameters, more complex models allowing asymmetry, that is, $\mathscr{S}(\mathrm{i}, \mathrm{j}) \neq \mathscr{P}(\mathrm{j}, \mathrm{i})$, can be created, but their necessity has not been demonstrated.

The problem here is to see if a model with few parameters will take up a sizable component of intertrial response variance, comparable with that modeled in other sensory modalities. In olfaction, the contrary view is that odor similarities are irregular and peculiar to the substances and chemical concentrations used, and are associated with a strong interaction of the mixture components (for example, see Köster, 1971, on possible cross-adaptation mechanisms within a mixture). If a particular mixture, however simple, can produce unique emergent qualities from the total sensory experience (which is the precise objective of some perfume blending), then its similarity with other mixtures is not going to be predictable from Model 1 or from Model 2, 3.

Separate analyses on the odorants used here (Gregson, 1982) show that amyl acetate intensity was the most consistently judged in the mixtures used, butanol was intermediate, and heptanol was most readily masked by its comembers. The associated values of $w_{1}$ should therefore decrease from $A$ through $B$ to $H$ pairs. This trend is of secondary importance but should occur if similarity judgment is a process that presupposes, as a prior phase, the psychophysics of detection and intensity perception on component odorants.

The mixtures are coded in terms of the substances used, and correspond to Table 1 . The root mean square residuals, E, are obtained over the total set of 28 similarity responses to the 56 stimulus mixtures, using the NAGFLIB (1978) Fortran algorithm E04FDF, run on a DEC-20 computer and based on a method by Gill and Murray (1978), which is a corrected Gauss-Newton unconstrained (no boundaries on w) nonlinear least-squares program for finding a 
Table 1

Experimental Plan

\begin{tabular}{|c|c|c|c|c|c|c|}
\hline \multirow{2}{*}{$\begin{array}{l}\text { Ses- } \\
\text { sion }\end{array}$} & \multicolumn{5}{|c|}{ Subjects } & \multirow[b]{2}{*}{ 6:S.A. } \\
\hline & 1:R.O. & 2:C.H. & 3:D.I. & 4:V.A. & 5:S.E. & \\
\hline 1 & $\mathrm{I}: \mathrm{AH}$ & $\mathrm{I}: \mathrm{BH}$ & I:BA & I:HA & I:HB & I: AB \\
\hline 2 & S:AH & $\mathrm{I}: \mathrm{HA}$ & $S: A B$ & $\mathrm{I}: \mathrm{AB}$ & S:BH & I:BH \\
\hline 3 & $\mathrm{I}: \mathrm{HB}$ & S:AH & I:AH & S:AB & I:BA & S:HB \\
\hline 4 & $\mathrm{I}: \mathbf{B A}$ & $\mathrm{I}: \mathrm{AB}$ & I:HB & $\mathrm{I}: \mathrm{BH}$ & I:AH & I:HA \\
\hline 5 & S:BH & S:HB & S:AH & S:HA & $\mathrm{S}: \mathrm{AB}$ & S:BA \\
\hline
\end{tabular}

Note-I = intensity judgments; $S=$ similarity judgments; $A=a m y l$ acetate; $B=$ butanol $; H=$ heptanol. All given as $X, Y$ flowline pairs.

minimum residual set of parameter values (w) given the function either $(1)$ or $(2,3)$. One cannot test (2) without (3) in this context.

The residuals $\mathrm{E}$ are high; to get an estimate of their meaning, postulate, as a maximum entropy prior distribution, that the $\mathscr{P}$ response values approximate a rectangular form. Then the expected absolute mean difference between theory and data is .33 (Kendall \& Stuart, 1977, p. 54). Hence, any $E>.3$ is indicative of a useless model, which eliminates $(2,3)$ in 10 cases out of 12. Subsequent consideration is therefore restricted to (1), allowing that there may exist other untested models better than $(2,3)$.

The form $(2,3)$, however, leads to numerical analysis problems unless $m_{h i}, m_{h j}$ are replaced by $\log \left(m_{h i}\right)$, $\log \left(m_{\mathrm{tj}}\right)$. Even with this, the distance $(2,3)$ model fitted worse than (1) in 9 cases out of 12 , which confirms previous findings (Gregson, 1976, 1980b) and is compatible with a more recent suggestion by Tversky and Gati (1982).

For (1), mean estimated $w_{1}$ (odorant) values are $w_{1}(A)=.89, w_{1}(B)=3.69$, and $w_{1}(H)=.99$. If a single extreme value of $W_{1}$ is excluded, the mean estimated $w_{1}$ (odorant) values are $w_{1}(A)=1.00, w_{1}(B)=1.48$, and $w_{1}(H)=.99$. An inference from these estimates is that butanol odor quality dominates in determining overall similarity when it is present, at least for some subjects. The mean estimated values for $w_{2}$ are $w_{2}(A)$ $=.69, w_{2}(B)=.78$, and $w_{2}(H)=.62$, which shows no trend.

The regression lines of observed on fitted $\mathscr{P}$ values should approximate to: $a=$ intercept $=0, b=$ slope $=1, \mathrm{r}^{2}>.20$, for a model to be of any value, whether or not the range of $\mathscr{S}$ values extends down to 0 . Due to the inherent low information capacity of olfaction as a sensory channel and to the strong sequential structure of odor experiments (Gregson, 1983), which is not incorporated in (1) or (2), there is a low ceiling to the amount of variance that these regressions can take up, no matter what model is fitted. The improvement in fit that is achieved here is dependent on the $w$; only if the partial derivatives $\partial E / \partial w_{1}$ and $\partial E / \partial w_{2}$ are not negligible and the model structure already approximates the processes modeled can fit be improved. In Table 2 , the comparison of regressions using (1) with fixed $w_{1}=1, w_{2}=.69$ (a mean value for the 12 sessions obtained from program E04FDF) and those using (1) with individual w values obtained from minimization of $E$ shows the extent of marginal improvement in cases where the fixed $w$ case fits at all. Regressions with low residuals but inappropriate $\mathrm{a}, \mathrm{b}$ regression parameters should be discounted. Excluding three cases where the algorithm produced a useless regression, mean $\mathbf{r}^{2}$ for fixed $w=$ .163 , and mean $\mathrm{r}^{2}$ for variable $\mathrm{w}=.252$, which implies that the adjustable parameter variance is about half the basic model structure variance. In Table 2, at the request of a referee, the $w$ values for model 2,3 are also given; it is doubtful if any coherent mean-

Table 2

Comparative Fitting of Models

\begin{tabular}{|c|c|c|c|c|c|c|c|c|c|c|c|c|c|}
\hline \multirow{3}{*}{$\begin{array}{c}\text { Sub- } \\
\text { ject } S\end{array}$} & \multirow{3}{*}{$\begin{array}{c}\text { Odor } \\
\text { Substances }\end{array}$} & \multicolumn{12}{|c|}{ Regression Parameters } \\
\hline & & \multicolumn{2}{|c|}{$\mathrm{E}=\mathrm{rms}$ Residuals } & \multicolumn{2}{|c|}{$w_{1}=1, w_{2}=.69$} & \multirow{2}{*}{$\frac{\mathrm{df}=25}{\mathrm{r}^{2}}$} & \multicolumn{2}{|c|}{$\begin{array}{c}\text { Variable } \\
\text { Weights }\end{array}$} & \multirow{2}{*}{$\frac{\mathrm{df}=24}{\mathrm{r}^{2}}$} & \multicolumn{2}{|c|}{$\begin{array}{l}\text { Coefficients for } \mathscr{P} \\
\text { Weighted Model } \\
\end{array}$} & \multicolumn{2}{|c|}{$\begin{array}{l}\text { Coefficients for } \\
\text { d Weighted } \\
\text { Model }(2,3)[\log \\
\text { (m) Values } \\
\text { Used] }\end{array}$} \\
\hline & & (1) & $(2,3)$ & a & $\mathrm{b}$ & & a & $\mathbf{b}$ & & $w_{1}$ & $\mathrm{w}_{2}$ & $w_{1}$ & $w_{2}$ \\
\hline 1:R.O. & $\begin{array}{l}\text { AH } \\
\text { HB }\end{array}$ & $\begin{array}{l}.276 \\
.255\end{array}$ & $\begin{array}{l}.333 \\
.294\end{array}$ & $\begin{array}{r}-.05 \\
.12\end{array}$ & $\begin{array}{l}.01 \\
.60\end{array}$ & $\begin{array}{l}.21 \\
.14\end{array}$ & $\begin{array}{l}.05 \\
.15\end{array}$ & $\begin{array}{l}.89 \\
.69\end{array}$ & $\begin{array}{l}.25 \\
.18\end{array}$ & $\begin{array}{l}1.36 \\
1.63\end{array}$ & $\begin{array}{l}.73 \\
.60\end{array}$ & $\begin{array}{r}.75 \\
1.03\end{array}$ & $\begin{array}{l}.10 \\
.10\end{array}$ \\
\hline 2:C.H. & $\begin{array}{l}\text { HA } \\
\text { BH }\end{array}$ & $\begin{array}{l}.305 \\
.343\end{array}$ & $\begin{array}{l}.345 \\
.381\end{array}$ & $\begin{array}{l}.14 \\
.08\end{array}$ & $\begin{array}{l}.54 \\
.61\end{array}$ & $\begin{array}{l}.05 \\
.06\end{array}$ & $\begin{array}{r}-.05 \\
.16\end{array}$ & $\begin{array}{r}1.09 \\
.69\end{array}$ & $\begin{array}{l}.25 \\
.15\end{array}$ & $\begin{array}{r}.93 \\
3.27\end{array}$ & $\begin{array}{l}.71 \\
.73\end{array}$ & $\begin{array}{r}14.11 \\
.96\end{array}$ & $\begin{array}{l}.35 \\
.10\end{array}$ \\
\hline 3:D.I. & $\begin{array}{l}\text { AB } \\
\text { AH }\end{array}$ & $\begin{array}{l}.400 \\
.300\end{array}$ & $\begin{array}{l}.354 \\
.352\end{array}$ & $\begin{array}{l}.07 \\
.48\end{array}$ & $\begin{array}{r}.65 \\
-.10\end{array}$ & $\begin{array}{l}.09 \\
.01\end{array}$ & $\begin{array}{l}.02 \\
.41\end{array}$ & $\begin{array}{r}.98 \\
0\end{array}$ & $\begin{array}{l}.23 \\
00\end{array}$ & $\begin{array}{l}.89 \\
.83\end{array}$ & $\begin{array}{l}.96 \\
.78\end{array}$ & $\begin{array}{l}.75 \\
.83\end{array}$ & $\begin{array}{l}.08 \\
.10\end{array}$ \\
\hline 4:V.A. & $\begin{array}{l}\mathrm{AB} \\
\mathrm{HA}\end{array}$ & $\begin{array}{l}.365 \\
.284\end{array}$ & $\begin{array}{l}.358 \\
.312\end{array}$ & $\begin{array}{l}.23 \\
.07\end{array}$ & $\begin{array}{l}.37 \\
.62\end{array}$ & $\begin{array}{l}.05 \\
.12\end{array}$ & $\begin{array}{l}.31 \\
.16\end{array}$ & $\begin{array}{l}.34 \\
.66\end{array}$ & $\begin{array}{l}.04 \\
.17\end{array}$ & $\begin{array}{l}1.29 \\
1.96\end{array}$ & $\begin{array}{l}.68 \\
.70\end{array}$ & $\begin{array}{l}.99 \\
.62\end{array}$ & $\begin{array}{l}.10 \\
.11\end{array}$ \\
\hline 5:S.E. & $\begin{array}{l}\text { HB } \\
\text { BA }\end{array}$ & $\begin{array}{l}.358 \\
.280\end{array}$ & $\begin{array}{l}.351 \\
.321\end{array}$ & $\begin{array}{l}.56 \\
.04\end{array}$ & $\begin{array}{l}.14 \\
.95\end{array}$ & $\begin{array}{l}.01 \\
.33\end{array}$ & $\begin{array}{l}.46 \\
.05\end{array}$ & $\begin{array}{l}.28 \\
.89\end{array}$ & $\begin{array}{l}.02 \\
.37\end{array}$ & $\begin{array}{r}.73 \\
19.14\end{array}$ & $\begin{array}{l}.41 \\
.48\end{array}$ & $\begin{array}{l}.61 \\
.55\end{array}$ & $\begin{array}{l}.14 \\
.13\end{array}$ \\
\hline 6:S.A. & $\begin{array}{l}\text { BH } \\
\text { AB }\end{array}$ & $\begin{array}{l}.255 \\
.215\end{array}$ & $\begin{array}{l}.314 \\
.277\end{array}$ & $\begin{array}{r}-.16 \\
.04\end{array}$ & $\begin{array}{l}.92 \\
.64\end{array}$ & $\begin{array}{l}.30 \\
.17\end{array}$ & $\begin{array}{l}.04 \\
.01\end{array}$ & $\begin{array}{l}.85 \\
.94\end{array}$ & $\begin{array}{l}.31 \\
.36\end{array}$ & $\begin{array}{r}2.03 \\
.69\end{array}$ & $\begin{array}{l}.74 \\
.80\end{array}$ & $\begin{array}{l}.57 \\
.94\end{array}$ & $\begin{array}{l}.10 \\
.09\end{array}$ \\
\hline
\end{tabular}


ing can be attached to them precisely because the residuals are too high.

Ancillary calculations showed no relation between the identity of odorants in mixtures, or the number of prior sessions, and the goodness of fit of model 1. This suggests that if the between-odorant similarities $\mathscr{P}_{12}$ are a factor, their action is uniform over all the pairs used.

Corollaries of model properties. Tversky and Gati (1982) comment that "similarity may be better characterized as a feature matching process ... than as a metric distance function"' (p. 153). This conclusion is consistent with that reached earlier and independently by Gregson (1975, and work cited therein); it should be noted that (1) is a form of feature matching, as are all models which predicate comparisons between countable features (dimensions, components) in terms of their intersection (minima) and union (maxima). (See Gregson, 1975, page 170ff).

A property of some similarity judgments which render them incompatible with distance representations is noted by Tversky and Gati (1982) as "the addition of the same feature to a pair of ... stimuli increases the similarity between them."

If $m_{i}$ is a subthreshold stimulus, $m_{i x}=m_{j x}$ is a fixed detectable component on dimension $x$, and $m_{i e}, m_{j b}$ are two unequal components on dimension $a$, then this property may be expressed as

$$
\begin{aligned}
& \left(\mathrm{m}_{\mathrm{o}}, \mathrm{m}_{\mathrm{ia}}\right) \mathscr{P}\left(\mathrm{m}_{\mathrm{o}}, \mathrm{m}_{\mathrm{jb}}\right)=\left(\mathrm{m}_{\mathrm{ia}}\right) \mathscr{P}\left(\mathrm{m}_{\mathrm{jb}}\right), \\
& \left(\mathrm{m}_{\mathrm{ix}}, \mathrm{m}_{\mathrm{ia}}\right) \mathscr{P}\left(\mathrm{m}_{\mathrm{jx}}, \mathrm{m}_{\mathrm{jb}}\right)>\left(\mathrm{m}_{\mathrm{ia}}\right) \mathscr{P}\left(\mathrm{m}_{\mathrm{jb}}\right) .
\end{aligned}
$$

As this experiment has no "mixtures" with one component, (4) and (5) are not directly testable. Some other properties may, however, be noted. Consider a set of six mixture pairs with fixed unequal components on one dimension and the same, but variable, components on the other:

$$
\begin{aligned}
& \text { dimension } 1 \text { dimension } 2\left(m_{x}\right) \\
& \begin{array}{rrr}
\text { mixture i } & 150 & 0,100,200,300,400,500 \\
\text { mixture j } & 50 & 0,100,200,300,400,500
\end{array}
\end{aligned}
$$

using $w_{1}=1.2, w_{2}=.7$ for (1) as typical values, and $w_{1}=1.2, w_{2}=.1$ for $(2,3)$ to give comparable results. The similarities $\mathscr{P}(\mathrm{i}, \mathrm{j})$ are shown in Table 3.

We have, in (4) and (5), suggested two mechanisms that would affect odor similarities: (4) because masking of weak components occurs and (5) as a consequence of general theory about similarities derived over other sensory modalities. Table 4 gives for illustration 5 of the 28 trials, to show the range, including all the cases in which, fortuitously, one component flow was fixed equal in the two mixtures.
Table 3

Theoretical Similarities for Two Models

\begin{tabular}{|c|c|c|c|c|c|c|}
\hline & \multicolumn{6}{|c|}{$\mathrm{m}_{\mathrm{x}}$} \\
\hline & 0 & 100 & 200 & 300 & 400 & 500 \\
\hline $\begin{array}{l}\text { For }(1) \\
\text { For }(2,3)\end{array}$ & .463 & .647 & $\begin{array}{r}.709 \\
\text { Consta }\end{array}$ & $\begin{aligned} & .745 \\
= & .786\end{aligned}$ & .774 & .795 \\
\hline
\end{tabular}
in the One Variable Equal Component and One Constant Unequal Component Case

In Table 4, a comparison of the two cells marked with a * does constitute some support for the Tversky and Gati conclusion, depending, however, on what monotone transformation of the flow rates is used as input to (2). There are no sequences within the 28 trials that can be used to test directly the predictions of Table 3.

As odors are usually blended into perfumes, which have a large number of ingredients (15-40 is not unknown; see Wells \& Billot, 1981), the presence of a single odorant must be detectable if it is to give a distinctive character (i.e., a dissimilarity from other mixtures) when it is present. The detectability of a single component odorous substance will be in part a function of the pairwise $\mathscr{P}_{\mathrm{gh}}, \mathrm{g}, \mathrm{h}=1,2, \ldots$, in an $\mathrm{n}$ component mixture. It is, therefore, necessary to assume that all $\mathscr{P}_{\mathrm{gh}}$ are small enough for component pairwise discriminability to obtain. Consider the four mixtures of $C_{1}$ and $C_{2}$

$\begin{array}{cccc}\alpha & \beta & \gamma & \delta \\ 2000 & 3000 & 30020 & 3001010,\end{array}$

where obviously $\alpha$ is a weak case of $C_{1}, \beta$ is a stronger

\begin{tabular}{|c|c|c|}
\hline Mixtures & $\begin{array}{l}\text { Mean Similarity } \\
\text { on } 12 \text { Data Sets }\end{array}$ & SD \\
\hline 100500 & .223 & $.218^{* *}$ \\
\hline 650400 & & \\
\hline $200 * 300$ & .572 & .346 \\
\hline $500 \quad 300$ & & \\
\hline 800200 & .689 & .331 \\
\hline $800 \quad 50$ & & \\
\hline $300 \quad 300$ & .697 & .351 \\
\hline 300500 & & \\
\hline $800 * 650$ & .815 & $.196 \dagger$ \\
\hline $500 \quad 650$ & & \\
\hline
\end{tabular}
case, $\gamma$ is $\beta$ with a "note" of $C_{2}$ added, $\delta$ is $\beta$ but with two different weak additions, $C_{2}$ and $C_{3}$. Using $w$

Table 4

Note-In each cell, the flow rates in milliliters/minute correspond to

$$
\left|\begin{array}{ll}
m_{i_{1}} & m_{i_{2}} \\
m_{j_{1}} & m_{j_{2}}
\end{array}\right|
$$

*Cells compared, giving support for Tversky and Gati (1982) conclusion. **Minimum mean. TMaximum mean. 
values, as before, the triangular diagrams of Figure 2 show predicted values from the two similarity models used.

The case of threshold masking in Figure 2 refers to the $\mathrm{C}_{2}$ component being made undetectable, as in (4). The differences between the predictions of the two models are small and depend critically on the choice of $w$ values; the diagrams are presented to show that it is possible to construct cases in which (1) may be of more value in representing effects that are created by adding small odor "notes" while at the same time meeting (4) and (5).

\section{EXPERIMENT 2}

The competing predictions of models 1 and 2, 3, as implied in the hypothetical case of Table 3, were subsequently examined using as odorants $n$-butanol and citronellal (Givaudan). These are distinctive and discriminable, and suprathreshold at all nonzero flow rates. Fourteen subjects in the age range of 17 40 years served as volunteers.

The flow-rate settings used are set out in Table 5. This gives 14 mixture pairs in all, each presented twice in a randomized sequence of 28 trials. Each similarity judgment is thus one of the four types (order $\times$ laterality): $\left(100, \mathrm{~m}_{\mathrm{x}}\right) \mathscr{S}\left(350, \mathrm{~m}_{\mathrm{x}}\right),\left(\mathrm{m}_{\mathrm{x}}, 100\right)$ $\mathscr{P}\left(\mathrm{m}_{x}, 350\right),\left(350, \mathrm{~m}_{x}\right) \mathscr{P}\left(100, \mathrm{~m}_{x}\right)$ and $\left(100, \mathrm{~m}_{x}\right) \mathscr{P}$ $\left(350, \mathrm{~m}_{\mathrm{x}}\right)$. As noted, Model 1 predicts that $\mathscr{P}$ is monotone increasing on $\mathrm{m}_{\mathrm{r}}$, and Model 2, 3 predicts that $\mathscr{S}$ is independent of $\mathrm{m}_{x}$, provided in both cases that component dimensions are not interactive, which is as the models are written. (Compare with the treatment of this consideration by Wiener-Ehrlich, Bart, \& Millward, 1980.)

Mean $\mathscr{S}$ values for each of the four replication $\times$ laterality combinations (order averaged out) and overall means are given in Table 6 . The major $F$ ratios associated with the values in Table 6 are given in Table 7; other values are either nonsignificant or involve replications $\operatorname{RT}(1,4)$ and $\operatorname{RLT}(1,1,3)$, for which the global test is insignificant, under transformation to minimize heteroscedascity.

The BMDP2V program was used to treat the data as a three-way within-subjects ANOVA, replication

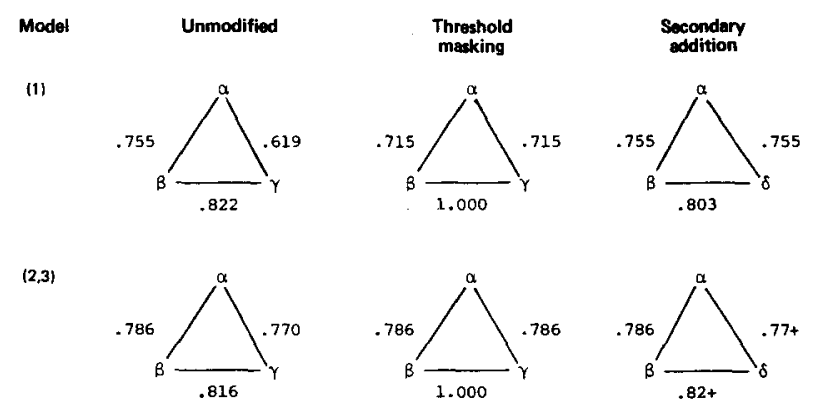

Figure 2. Theoretical similarities between mixtures $\alpha, \beta, \gamma, \delta$.
Table 5

Flow Rate Settings in Milliliters/Minute for Mixtures Used in Experiment 2

\begin{tabular}{lrc}
\hline & Dimension 1 & Dimension 2 $\left(\mathrm{m}_{\mathrm{x}}\right)$ \\
\hline Mixture $\mathrm{i}$ & 350 & $0,50,100,200,400,600,800$ \\
Mixture j & 100 & $0,50,100,200,400,600,800$ \\
\hline
\end{tabular}

$\times$ laterality $\times \mathrm{m}_{\mathbf{x}}$. There are statistical complications to this course because: (1) the data do not fully satisfy sphericity tests; (2) a transform of $\mathscr{S}$ to $\mathscr{S}^{2}$ is needed (Box \& Cox, 1964) to reduce the correlation between log cell means and log cell standard deviations, since the variance of $\mathscr{P}$ responses is maximized at midrange and minimal at extremes (Gregson, 1976), and hence for the range of mean values met here (.413.849) will show the negative correlation given in Table 7; (3) second-order perturbations to the linear trend can arise because some $m_{x}$ are below minimum $m_{A}(=100)$ and some $m_{x}$ are above maximum $m_{A}$ $(=350)$ (cf. Gregson, 1980a); and (4) the perceived intensity of the two substances is not exactly the same for the same flow settings; that is, $\psi\left(m_{A}\right) \neq \psi\left(m_{B}\right)$, given $m_{A}=m_{B}=X$.

The overall mean trend is consistent with model 4, but with the complication of a dip at $m_{x}=400$. The average trend has at least four turning points, as reflected in the $m$ (sextic) orthogonal component and in the laterality $\times \mathrm{m}$ (quintic) terms. Three terms, $\mathrm{m}(1), \mathrm{m}(6), \operatorname{Lm}(1,5)$, are all robust for transformations over the range $\mathscr{S}^{\prime}=\mathscr{S}$ to $\mathscr{S}^{\prime}=\mathscr{S}^{2}$ and so may be accepted. The main effects not orthogonally decomposed are also given the Greenhouse-Geisser and Huynh-Feldt probabilities for comparison. None of these alternatives affect the interpretation.

This second experiment confirms the major finding and prediction of the first, namely that Model 1 is supported and Model 2, 3 is disconfirmed.

\section{DISCUSSION}

Results on the odor pairs used here are compatible with some previous findings on similarities in other modalities, and with two reported cases of odor mixture data. They are contraindicative for metric space assumptions and also suggest new testable corollaries. There are no published data on three-component odor mixtures that can be used to test the models set up here.

A further complication exists which makes invalid comparison between multidimensional scaling of $\mathscr{P}_{\text {ij }}$ data of unknown mixture composition and the modeling here with $\mathscr{F}_{12}$ supposed negligible. In scaling sets of odorants, a dominant dimension is often the hedonic tone of the stimuli (Coxon, Gregson, \& Paddick, 1978; Gregson \& Mitchell, 1974; Yoshida, 1972), since pleasantness-unpleasantness is a more readily used basis for judgment than is odor type, for 
Table 6

Mean Similarity Ratings for Different $m_{x}$ Values in Experiment 2

\begin{tabular}{rccccc}
\hline \multicolumn{5}{c}{ Replications Laterality } \\
\hline $\mathrm{m}_{\mathrm{x}}$ & 1,1 & 1,2 & 2,1 & 2,2 & $\overline{\mathrm{y}}$ \\
\hline 0 & 61.3 & 56.8 & 59.4 & 43.9 & 55.33 \\
50 & 60.7 & 58.6 & 61.9 & 71.4 & 63.15 \\
100 & 68.4 & 55.4 & 70.0 & 64.8 & 64.65 \\
200 & 73.6 & 81.3 & 65.0 & 68.6 & 72.13 \\
400 & 47.9 & 83.9 & 41.3 & 75.0 & 62.03 \\
600 & 65.7 & 84.9 & 80.2 & 71.1 & 75.47 \\
800 & 84.4 & 82.6 & 67.4 & 76.4 & 77.7 \\
\hline
\end{tabular}

untrained observers. In this study, the hedonic variability within a session is slight, mixtures in a series being all qualitatively related. So the bases of judgments may exclude one which maps into a major dimension when a very diverse set of odorants is used.

One vector model of similarity fitted by Stockholm investigators (Gregson, 1975, chap. 3) predicted that the similarity between two unidimensional stimuli of the same qualitative type is a ratio of the minimum intensity divided by the average intensity, which is not quite the same as (1) with only one component nonzero. However, the property noted by Tversky and Gati consequent upon adding a constant second component (and even more distinguishable constant components) will follow if the interdimensional $\mathscr{S}_{12}$

Table 7

\begin{tabular}{|c|c|c|c|c|c|}
\hline \multirow[b]{3}{*}{ Source } & \multicolumn{5}{|c|}{ Transform } \\
\hline & \multicolumn{3}{|c|}{$y^{\prime}=y^{2}$} & \multicolumn{2}{|c|}{$y^{\prime}=y$} \\
\hline & $\mathbf{F}$ & df & $\mathrm{p}$ & $\mathbf{F}$ & $\mathbf{p}$ \\
\hline $\begin{array}{l}\text { Repl } \\
\text { Laty } \\
R \times L \\
m(1) \\
m(6) \\
m\end{array}$ & $\begin{array}{r}1.83 \\
1.61 \\
0.18 \\
13.30 \\
6.51 \\
3.58\end{array}$ & $\begin{array}{l}1,13 \\
1,13 \\
1,13 \\
1,13 \\
1,13 \\
6,78\end{array}$ & $\begin{array}{l}.20 \\
.23 \\
.67 \\
.003 \\
.024 \\
.0035\end{array}$ & $\begin{array}{r}1.71 \\
2.12 \\
0.22 \\
16.23 \\
5.27 \\
3.38\end{array}$ & $\begin{array}{l}.21 \\
.17 \\
.64 \\
.001 \\
.04 \\
.005\end{array}$ \\
\hline $\begin{array}{l}\text { G-G } \\
\text { H-F }\end{array}$ & & & $\begin{array}{l}.0205 \\
.0103\end{array}$ & & $\begin{array}{l}.0239 \\
.0120\end{array}$ \\
\hline $\begin{array}{l}\operatorname{Lm}(1,1) \\
\operatorname{Lm}(1,5) \\
\operatorname{Lm}\end{array}$ & $\begin{array}{r}4.62 \\
10.89 \\
3.10\end{array}$ & $\begin{array}{l}1,13 \\
1,13 \\
6,78\end{array}$ & $\begin{array}{l}.0601 \\
.0058 \\
.0090\end{array}$ & $\begin{array}{l}3.65 \\
8.67 \\
3.10\end{array}$ & $\begin{array}{l}.0785 \\
.0114 \\
.0089\end{array}$ \\
\hline $\begin{array}{l}\text { G-G } \\
H-F\end{array}$ & & & $\begin{array}{l}.0273 \\
.0126\end{array}$ & & $\begin{array}{l}.0276 \\
.0129\end{array}$ \\
\hline $\mathrm{Rm}$ & 0.93 & 6,78 & .4799 & 0.92 & .4842 \\
\hline $\begin{array}{l}\text { G-G } \\
H-F\end{array}$ & & & $\begin{array}{l}.4490 \\
.4715\end{array}$ & & $\begin{array}{l}.4543 \\
.4782\end{array}$ \\
\hline RLM & 1.03 & 6,78 & .4105 & 0.82 & .5567 \\
\hline $\begin{array}{l}\text { G-G } \\
\text { H-F }\end{array}$ & & & $\begin{array}{l}.3943 \\
.4053\end{array}$ & & $\begin{array}{l}.4997 \\
.5309\end{array}$ \\
\hline \multicolumn{4}{|c|}{${ }^{{ }^{\mathrm{t}}} \log \bar{y} \cdot \log \sigma=-.1828$} & \multicolumn{2}{|c|}{-.6373} \\
\hline
\end{tabular}

Note-Repl $=$ replications $($ sessions effect $) ;$ Laty $=$ laterality (component fixed as $m_{\mathrm{x}}$ ); $m(n)=n$th orthogonal component of polynormal trend of similarity on $m_{\mathbf{x}}$ concentration; $G-G=$ Greenhouse-Geisser; H-F $=$ Huynh-Feldt. are negligible over all pairwise comparisons involving the dimension on which there is a real difference.

It is concluded that some odor mixture similarity judgments, under restricted stimulus conditions, are mediated by comparable central processes (and hence map into the same model) as are some similarities not involving olfaction. The results are intrinsically very noisy and hence for some observers uninterpretable.

A recent conclusion by Engen (1982, p. 123) that odor "primarily transmits information of qualitative similarity of percepts rather than psychophysical differences in intensity" appears to need reconsideration. The method and results given here suggest that a mix of intensity psychophysics and similarity of percepts is always present, and that the latter is in some way controllable through the former.

\section{CONCLUSIONS}

This study focused on the possibility that regularities in odor mixture similarities, although intrinsically based on a noisy psychophysical process, could be represented by models already found to be applicable in other modalities in which similarities could be related to stimulus mixture pairs, given that each such stimulus has identifiable and quantifiable physical component magnitudes. From previous comparative evaluations of different models, drawn from two families which were (a) transformed distances and (b) set theoretic measures, it was expected that the set theoretic family would include a better model. The model 1 used in this study is not isomorphic with a distance representation, although in some cases equivalences between special cases in the two families can be constructed (Gregson, 1976). The inapplicability of distance as a representation of similarity has been indicated by a diversity of previous studies; this result confirms and extends the finding to odor mixtures of simple composition.

In the specific context of olfaction, further complications exist to attenuate the fit of any simple model; interdimensional masking and intradimensional threshold effects have been specifically noted and their consequences predicted and tentatively identified. Some of these second-order effects can be predicted from univariate psychophysics, but others necessarily will arise only in mixtures of two or more components.

There remains the serious problem of bridging the gap between modeling what occurs when the human observer compares simple mixtures of two odors, both suprathreshold, and what happens when we perceive the qualities of two or more perfumes, each with many components. The substitutability of one complex odor for another is a fact upon which whole industries have grown up, but the psychophysics of odor mixture similarities is still inadequate to serve as a conceptual foundation for our understanding of the sensory and esthetic processes in complex olfaction. 


\section{REFERENCES}

Amoore, J. E., \& Venstrom, D. Correlations between stereochemical assessments and organoleptic analysis of odorous compounds. In T. Hayashi (Ed.), Taste and odor II. Oxford and New York: Pergamon Press, 1967.

Box, G. E. P., \& Cox, D. R. An analysis of transformations. Journal of the Royal Statistical Society, Series B, 1964, 26, 211-252.

Coxon, J. M., Gregson, R. A. M., \& Paddick, R. G. Multidimensional scaling of perceived odor of bicyclo(2.2.1)heptane, 1,7,7-trimethylbicyclo(2.2.1)heptane and cyclohexane derivatives. Chemical Senses and Flavor, 1978, 3, 431-441.

Davis, R. G. Acquisition and retention of verbal associations to olfactory and abstract visual stimuli of varying similarity. Journal of Experimental Psychology: Human Learning and Memory, 1977, 3, 37-51.

DAvis, R. G. The microencapsulation of odorants as a method of stimulus control and delivery in studies of odor quality perception. Chemical Senses and Flavor, 1979, 4, 191-206.

ENGEN, T. The perception of odors. New York: Academic Press, 1982.

Gill, P. E., \& Murray, W. Algorithms for the solution of the non-lipear least squares problem. SIAM Journal on Numerical Analysis, 1978, 15, 977-992.

Gregson, R. A. M. Odor similarities and their multidimensional metric representation. Multivariate Behavioral Research, 1972, 7, 165-174.

Gregson, R. A. M. Psychometrics of similarity. New York: Academic Press, 1975.

Gregson, R. A. M. A comparative evaluation of seven similarity models. British Journal of Mathematical and Statistical Psychology, 1976, 29, 139-156.

Gregson, R. A. M. A model of paradoxical odor mixture perception. Chemical Senses and Flavor, 1980, 5, 257-269. (a)

Gregson, R. A. M. Model evaluation via stochastic parameter convergence as on-line system identification. British Journal of Mathematical and Statistical Psychology, 1980, 33, 17-35. (b)

Gregson, R. A. M. Representation of a 2-input, 2-output odour mixture identification task as a multivariate time series. In Proceedings of the 2nd Australian Mathematical Psychology Conference, Newcastle, N.S.W: University, 1982.

Gregson, R. A. M. The sequential structure of odour mixture component intensity judgments. British Journal of Mathematical and Statistical Psychology, 1983, 36, 132-144.

Gregson, R. A. M., \& Mitche LL, M. J. Odor quality similarity scaling and odor-word profile matching. Chemical Senses and Flavor, 1974, 1, 95-101.

Harpen, R., BAte-SMith, E. C., \& LAND, D. G. Odour description and odour classification. London: Churchill, 1968.
Jones, F. N., Roberts, K., \& Holman, E. W. Similarity judgments and recognition memory for some common spices. Perception \& Psychophysics, 1978, 24, 2-6.

Kendall, M., \& Stuart, A. The advanced theory of statistics (Vol. 1): Distribution theory (4th ed.). London: Griffin, 1977.

Köste R, E. P. Adaptation and cross-adaptation in olfaction. Rotterdam: Bronder, 1971.

Lopes, L. L., \& Oden, G. C. Comparison of two models of similarity judgment. Acta Psychologica, 1980, 46, $205-234$.

Mitchelt, M. J. Investigations of olfactory similarity scaling. Unpublished doctoral thesis, University of Canterbury, New Zealand, 1971.

NAGFLIB-Mark 7 (Program Library). Oxford: Numerical Algorithms Group, 1978.

Schiffman, S., Robinson, D. E., \& Erickson, R. P. Multidimensional scaling of odorants: Examination of psychological and physicochemical dimensions. Chemical Senses and Flavor, $1977,2,375-390$.

Shepard, R. N., \& Arabie, P. Additive clustering: Representation of similarities as combinations of discrete overlapping properties. Psychological Review, 1979, 86, 87-123.

Tvensky, A. Features of similarity. Psychological Review, 1977, 84, 327-352.

Tversky, A., \& Gati, I. Similarity, separability and the triangle inequality. Psychological Review, 1982, 89, 123-154.

Wells, F. V., \& Billot, M. Perfumery technology, art:science: industry (2nd ed.). Chichester: Ellis Horwood, 1981.

Wiener-Ehrlich, W. K., Bart, W. M., \& Millward, R. An analysis of generative representation systems. Journal of Mathematical Psychology, 1980, 21, 219-246.

Woskow, M. Multidimensional scaling of odors. Unpublished doctoral dissertation, University of California, Berkeley, 1964.

Wright, H. R., \& Michels, K. M. Evaluation of far infrared relations to odor by a standards similarity method. Annals of the New York Academy of Sciences, 1964, 116, 535-551.

YoshidA, M. Studies in psychometric classification of odors. Japanese Psychological Research, 1972, 14, 101-108.

\section{NOTE}

1. The $\mathscr{P}$ notation, and (x) $\mathscr{P}(\mathrm{y})$ notation here follows Gregson (1975); $\mathscr{f}$ is a real positive number in the range 0,1 , or the properties of the pair $(x, y)$ are mapped by the operation $\mathscr{S}$ into the real line.

(Manuscript received April 4, 1983; revision accepted for publication September 30, 1983.) 